\title{
Crumb Rubber Effect on Acoustic Properties of Self- Consolidating Concrete
}

\author{
Malek Jedidi $^{\text {a,b, } * \text {, Ali Boulila }}{ }^{a}$, Omrane Benjeddou ${ }^{\text {a,b }}$, Chokri Soussi ${ }^{\text {a,c }}$ \\ ${ }^{a}$ Institut Supérieur des Etudes Tecnologiques de Sfax, Département de Génie Civil, B.P.88, 3099 Sfax, Tunisia \\ ${ }^{b}$ Université de Tunis El Manar, Ecole Nationale d'Ingénieurs de Tunis, Laboratoire de Génie Civil, B.P.37,Tunis \\ Belvédère, 1002,Tunisia \\ ${ }^{c}$ Université de Sfax, Faculté des sciences de Sfax, Laboratoire de Géoressources, Matériaux, Environnement et \\ Changement Globaux, B.P.1171 Sfax, Tunisia
}

\begin{abstract}
Several researches have been conducted to find a practical and environmentally sound solution of the problem of scrap tires. In this context, an experimental study was conducted to provide more data on the effect of crumb rubber on the acoustic properties of self-consolidating concrete SCC. To this end, Parallelepiped and cylindrical specimens were prepared by varying the proportion of crumb rubber with percentages of $0 \%, 10 \%, 20 \%$ and $30 \%$ of the volume of gravel. Properties such standardized level difference, sound absorption at different frequency and noise reduction were investigated. The results showed that the sound absorption and noise reduction coefficient were increased according to the increase of the percentage of crumb rubber. The self-consolidating concrete rubber SCCR has better acoustic properties in comparison with SCC.
\end{abstract}

Keywords: Crumb rubber, Self-consolidating concrete, Standardized level difference, Sound absorption, Noise reduction, Sound transmission class.

\section{Introduction}

Each year more than three million tires are discarded reaching the end of life. This is a cumbersome waste and environmental pollution ecology destabilizes [1]. The use of waste in construction materials can meet the need of conservation of natural aggregate resources (especially that the country can pose a significant lack in aggregate) and can also protect the environment by reducing landfill only to final waste $[2,3]$.

There are many lightweight construction materials that contain recycled fillers such as fly ash [4], waste glass [5], steel slag [6], lightweight expanded clay aggregates [7], foam polystyrene [8] and more .Technological development in the manufacture of concrete through the creation of new additives allowed to make concrete more sophisticated including selfconsolidating concrete (SCC). This material is characterized by its fluidity, ease of implementation and ability to fill formwork heavily armed. The possibility of designing a self-compacting

${ }^{*}$ Corresponding author. Tel.: +21698258681

Fax: +21698258681; E-mail: malekjedidi@yahoo.fr

(C) 2014 International Association for Sharing Knowledge and Sustainability

DOI: $10.5383 /$ ijtee.08.02.002 concrete with rubber aggregates (SCCR) seems particularly interesting insofar as this material combines the properties of a SCC and of a material from the recycling of industrial waste which gives a cheapest composite [9]. The research into the SCCR remains limited because the addition of rubber aggregate in the concrete mixtures exhibits a loss in strength [10].

Several recent studies explore the increase in compatibility of crumb rubber aggregates when used as a replacement in SCC mixes. For example, Ei-dieb et al. [11] reported that by adding less than $10 \%$ rubber through the replacement of coarse aggregate does not significantly hinder the performance of the concrete, reducing strength by around $10-15 \%$. Jedidi et al. [12] found that the addition of the crumb rubber decreased the speed at which the heat is propagated in the material and thus increased specific heat. Eldin and Senouci [10] found that SCRR exhibits a ductile and plastic failure. Therefore, it has the ability to absorb a large amount of plastic energy under compressive and tensile loads. El-Gammal et al. [13] reported that, in general, the SCCR have acceptable workability in terms 
of ease of handling, placement, and finishing. The research conducted by Zheng [14] reported that Recent the addition of rubber can increase the vibration absorption of a concrete slab.

There is a wide-range of possible civil engineering applications for SCCR. Examples include architectural applications such pavements, floors, walls, false facades and stone backing [15]. It can still be used for the construction of footpath, driveways and selected road construction applications due to its high toughness qualities $[10,16,17]$. Therefore, SCCR can be used for applications requiring deformable concrete with high flowability and low/medium strength $(<35 \mathrm{MPa})$, which is difficult to achieve using SCC [18,19]. El-Gammal et al. [7] reported that SCCR can also be used in the production of road kerbs, and non-bearing concrete walls.

In order to understand the fundamental properties of SCCR and how it performs in its intended application, a study was undertaken to carefully monitor the production of SCCR, investigating the effect of adding crumb rubber in SCC on the fundamental acoustic properties such as standardized level difference, sound absorption and noise reduction using local materials and incorporating crumb rubber with percentages of $0 \%, 10 \%, 20 \%$ and $30 \%$ of the volume of gravel.

\section{Experimental study}

\subsection{Materials characteristics}

The cement used was a CEM I 32.5 in conformity with Tunisian Standard NT 47.01produced by the Cement Company of GABES. Table 1 shows the chemical composition and properties of the cement.

Table 1. Chemical composition and properties of cement

\begin{tabular}{lc}
\hline Chemical composition and properties & Cement (\%) \\
\hline $\mathrm{SiO}_{2}$ & 28.48 \\
$\mathrm{Al}_{2} \mathrm{O}_{3}$ & 4.19 \\
$\mathrm{Fe}_{2} \mathrm{O}_{3}$ & 3.77 \\
$\mathrm{CaO}$ & 56.26 \\
$\mathrm{MgO}$ & 0.89 \\
$\mathrm{SO}_{3}$ & 1.54 \\
$\mathrm{Specific}_{2}$ gravity & 3.10 \\
Specific surface area, $\mathrm{cm}^{2} / \mathrm{g}$ & 3800 \\
\hline
\end{tabular}

FAIDH's career is the source of the aggregates crushed limestone which was used for the preparation of concrete specimens. The rubber aggregates are obtained by grinding used of-life tires following two particle-size cuts $0 / 4$ and $4 / 8$ (Fig. 1). The properties of fine aggregate; coarse aggregate and crumb rubber are shown in Table 2.

Table 2. Properties of fine aggregate, coarse aggregate and crumb

\begin{tabular}{lccccc}
\multicolumn{4}{c}{ rubber } \\
\hline \multirow{2}{*}{ Properties } & $\begin{array}{c}\text { Fine } \\
\text { aggregate }\end{array}$ & \multicolumn{2}{c}{$\begin{array}{c}\text { Coarse } \\
\text { aggregate }\end{array}$} & \multicolumn{2}{c}{ Crumb rubber } \\
\cline { 3 - 6 } & & $4 / 8$ & $8 / 16$ & $0 / 4$ & $4 / 8$ \\
\hline Specific gravity & 2.61 & 2.73 & 2.76 & 0.95 & 0.95 \\
Absorption, \% & 3.20 & 2.50 & 2.40 & & \\
Fineness modulus & 2.51 & & & 0.92 & 0.90 \\
Los Angeles, \% & & 34 & 35 & & \\
\hline
\end{tabular}

The employed admixture was a superplasticizer (SP) of type Tempo 12 manufactured by SIKA. It is used to increase markedly the workability of concrete according to the requirements of NF EN 934-2+A1 [20]. The dosage was $1 \%$ by weight of cement. Table 3 gives the physicochemical characteristics of the SP.

Table 3. Physicochemical characteristics of the SP

\begin{tabular}{|c|c|c|c|c|}
\hline Density & $\mathrm{pH}$ & $\mathrm{Na}_{2} \mathrm{OEq}(\%)$ & Dry extract $(\%)$ & $\mathrm{CI}^{-}$ \\
\hline $1.06 \pm 0.01$ & 4.5 à 6.5 & $\leq 1 \%$ & 28.0 à 31.0 & $\leq 0.1 \%$ \\
\hline
\end{tabular}

\subsection{Crumb rubber manufacture processes}

Preparation of crumb rubber started in ambient mechanical grinding process, the breaking up of a scrap tire happens at or above normal room temperature. Ambient grinding is a multistep technology and uses whole or pre-treated car or truck tires in the form of shred or chips, or sidewalls or treads. The rubbers, metals and textiles are sequentially separated out. Tires are passed through a shredder, which breaks the tires into chips.

The chips are fed into a granulator that breaks them into small pieces while removing steel and fiber in the process. Any remaining steel is removed magnetically and fiber through a combination of shaking screens and wind sifters. Finer rubber particles can be obtained through further grinding in secondary granulators and high-speed rotary mills.
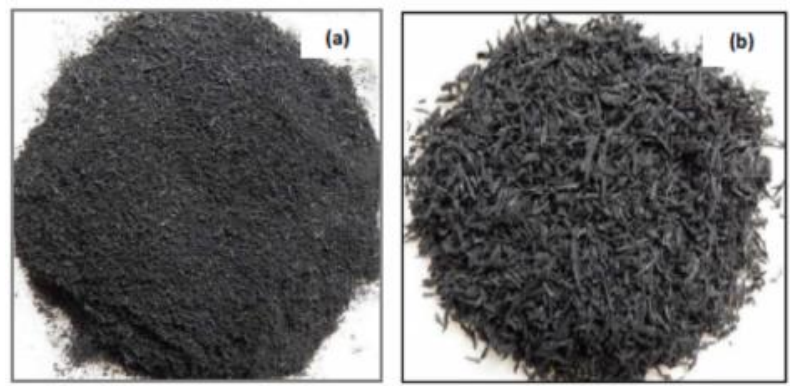

Fig. 1.Particle size of crumb rubber obtained from tires: (a) $0 / 4$, (b) $4 / 8$

\subsection{Mixtures}

Parallelepiped and cylindrical specimens were prepared by varying the proportion of crumb rubber with percentages of $0 \%, 10 \%, 20 \%$ and $30 \%$ of the volume of gravel. Table 4 shows the total number and size of the test specimens as well as adopted Standard test methods.

Table 4. Number and size of test specimens

\begin{tabular}{cccc}
\hline Test & Dimension & Number & Standard \\
\hline $\begin{array}{c}\text { Standardized } \\
\text { Level Difference }\end{array}$ & $\begin{array}{c}700 \mathrm{~mm} \times 700 \mathrm{~mm} \\
\text { x 50mm } \\
\text { Acoustic }\end{array}$ & 12 & EN ISO 717-1 \\
$\begin{array}{c}100 \mathrm{~mm} \text { dia } \times 10 \\
\mathrm{~mm}\end{array}$ & 16 & \\
$\begin{array}{c}\text { absorption and } \\
\text { transmission loss }\end{array}$ & Low frequency) & 16 & ISO 10534-2 \\
Density & $28 \mathrm{~mm}$ dia. $\times 10$ & & \\
& & 12 & $\begin{array}{c}\text { NF EN 12350- } \\
6\end{array}$ \\
\hline
\end{tabular}


The values $(0,10,20$, and 30$)$ indicate the proportion of crumb rubber by substitution of the volume of gravel. The SelfConsolidating Concrete and the Self-Consolidating Concrete with crumb rubber were respectively designated as SCC and SCCR.

The composition of all prepared mixtures is given in Table 5 . Effective water/cement ratio was 0.55 and kept constant in all mixtures. The parallelepiped specimens were used to determine the Standardized Level Difference. Cylindrical specimens of $100 \mathrm{~mm}$ and $28 \mathrm{~mm}$ diameter were used to determine the acoustic absorption and transmission loss. The noise reduction coefficient (NRC) was predicted from the value of sound absorption coefficients at different frequency.

Test specimens were kept in their molds. After $24 \mathrm{~h}$, they were removed from the mold and subjected to water curing at $20^{\circ} \mathrm{C}$. At the correspondent age, the specimens were taken out and kept in laboratory conditions until testing time.

Table 5.Composition of the mixtures

\begin{tabular}{lcccc}
\hline Materials & SCC0R & SCC10R & SCC20R & SCC30R \\
\hline Cem I 32.5 [Kg] & 350 & 350 & 350 & 350 \\
Gravel 4/8 & 540 & 486 & 432 & 258 \\
Gravel 8/16 & 360 & 360 & 360 & 360 \\
Sand [Kg] & 900 & 810 & 720 & 746 \\
Crumb rubber 0/4 & 0 & 41.4 & 82.3 & 70.8 \\
Crumb rubber 4/8 & 0 & 23.6 & 47.4 & 123.6 \\
Water [Kg] & 195 & 195 & 195 & 195 \\
Filers [Kg] & 100 & 100 & 100 & 100 \\
SP [Kg] & 7.7 & 7.7 & 8.8 & 9.5 \\
\hline
\end{tabular}

\section{Test Procedures}

\subsection{Equipment of test}

The acoustic measurements are taken on a test bench manufactured in the laboratory of Civil Engineering of the Higher Institute of Technological Studies of Sfax using the following measuring equipment:

- Omni Power sound Source: It is a speaker of polyhedric form comprising of the high speakers distributed on 12 faces. These high speakers give an adequate approximation of the uniform unidirectional emission. (Fig.2)

- Sonometer - 2260 Investigator: The sonometer 2260 Investigator is a precision hand-held sound level meter with real-time displays of $1 / 3$-octave and octave band spectra and statistical distributions. Also included is a PC compatible filing system and large memory. The 2260 conforms to the BS EN 61672 Class 1 standard.

- Power amplifier: it is an electronic amplifier that amplifies low-power audio signals (signals composed primarily of frequencies between $20-20000 \mathrm{~Hz}$, the human range of hearing) to a level suitable for driving loudspeakers. It is the final electronic stage in a typical audio playback chain.
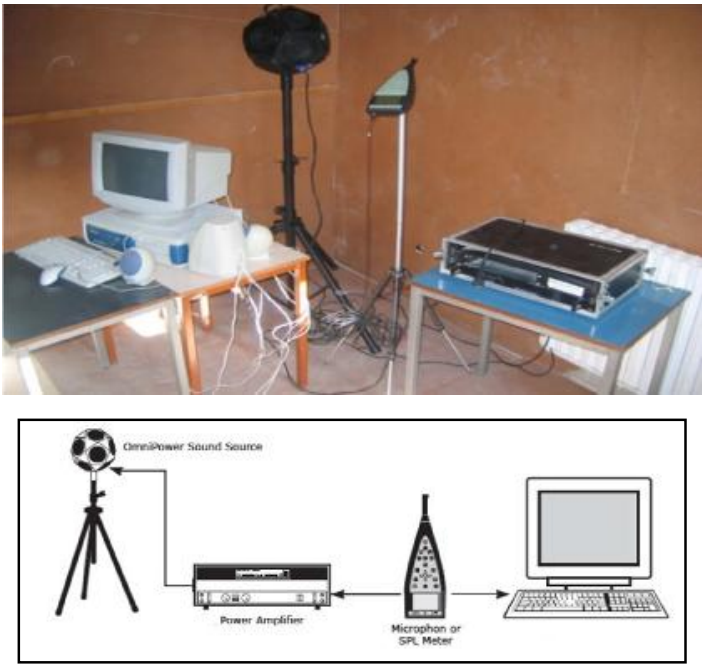

Fig. 2.Standardized Level Difference and reverberation time testing apparatus

\subsection{Measurement of acoustic properties}

\subsubsection{Level Difference}

The difference in the space and time average sound pressure levels produced in two rooms by one or more sound sources $n$ one of them. This quality is denoted by $\mathrm{D}$ :

$$
D=L_{1}-L_{2}
$$

Where $L_{1}$ is the average Sound Pressure Level in the source room, $\mathrm{L}_{2}$ is the average Sound Pressure Level in the receiving room

\subsubsection{Standardized Level Difference}

Airborne sound transmission. Similar to the level difference, but this index corrects the measured difference to a standardized reverberation time of 0.5 seconds. The adjustment is 10 times the logarithm of the ratio of the receiving room reverberation time and a reference reverberation time. This quantity is denoted by DnT:

$$
D n T=D+10 \log \frac{T_{r}}{T_{0}}
$$

Where $\mathrm{D}$ is the level difference, $\mathrm{Tr}$ is the reverberation time in seconds in the receiving room, T0 is the reference reverberation time in seconds, 0.5 seconds for dwellings.

\subsubsection{Acoustic absorption and transmission loss test}

A material has a good sound absorption if the absorption coefficient is close to 1 and it has an absorption plateau at this value on a wide range of frequency. However, indicating the sound properties of materials using the a-values at different frequency ranges would be complex, as it involves calculations over several frequencies. To solve this problem, the ability of material to absorb sound can be indicated using one single value called noise reduction coefficient (NRC). The NRC can be calculated using the following equation [21]:

$$
N R C=\frac{\alpha_{250}+\alpha_{500}+\alpha_{1000}+\alpha_{2000}}{4}
$$


Where $\alpha$ is the sound absorption coefficient at different frequency.

\subsubsection{Sound Transmission Class}

The Sound Transmission Class (STC) is a single number rating of the effectiveness of a material or construction assembly to retard the transmission of airborne sound. The sound transmission loss between the source and receiving rooms are plotted on a graph by frequency and sound level in decibels. The STC curve is a sliding contour that is fitted to the performance data plotted in a manner that will allow no more than 32 deficiencies below the appropriate contour.

The STC is determined by comparing the set of transmission losses at all 16 1/3 octave center frequencies to a set of standard contours as described in ASTM Standard E413-70T [22].The maximum deficiency at any given frequency shall not exceed 8 decibels.

Once the appropriate contour has been selected the STC is determined by the decibel value of the vertical scale at $500 \mathrm{~Hz}$. The STC is expressed as a single STC number.

\subsection{Measurement of Standardized Level Difference}

The device used to determine Standardized Level Difference of the sample (Fig.2) is composed as follows:

- An acoustic chamber within which the sample is placed as separation between the source room and the receiving room.

- An Omni power sound source (S) supplied by a power amplifier is placed in the source room.

- A sonometer connected to a microcomputer is placed in the receiving room to measure sound pressure levels inside the box.

\section{$1^{\text {st }}$ measure}

The Omni power sound source (S) and the sonometer are placed in the source room in order to measure the average sound pressure level $\mathrm{L}_{1}$. (Fig.3.a)

\section{$2^{\text {nd }}$ measure}

The sonometer was moved in the receiving room in order to measure the average sound pressure level L2. (Fig.3.b)

\section{$3^{\text {nd }}$ measure}

The source is brought back in receiving room local for the measurement of the reverberation time Tr. (Fig.3.c).

$\mathrm{T}_{\mathrm{r}}$ is the time required for reflections of a direct sound to decay $60 \mathrm{~dB}$.

$T_{r}$ is frequently stated as a single value, if measured as a wide band signal $(20 \mathrm{~Hz}$ to $20 \mathrm{kHz})$, however, being frequency dependent, it can be more precisely described in terms of frequency bands (one octave, 1/3 octave, 1/6 octave, etc.).

In this study, the sonometer measures the reverberation time for a signal to drop by $30 \mathrm{~dB}$. The reverberation time for a signal to drop by $60 \mathrm{~dB}$ was determined by the following equation:

$$
T_{60}=2 \times T_{30}
$$
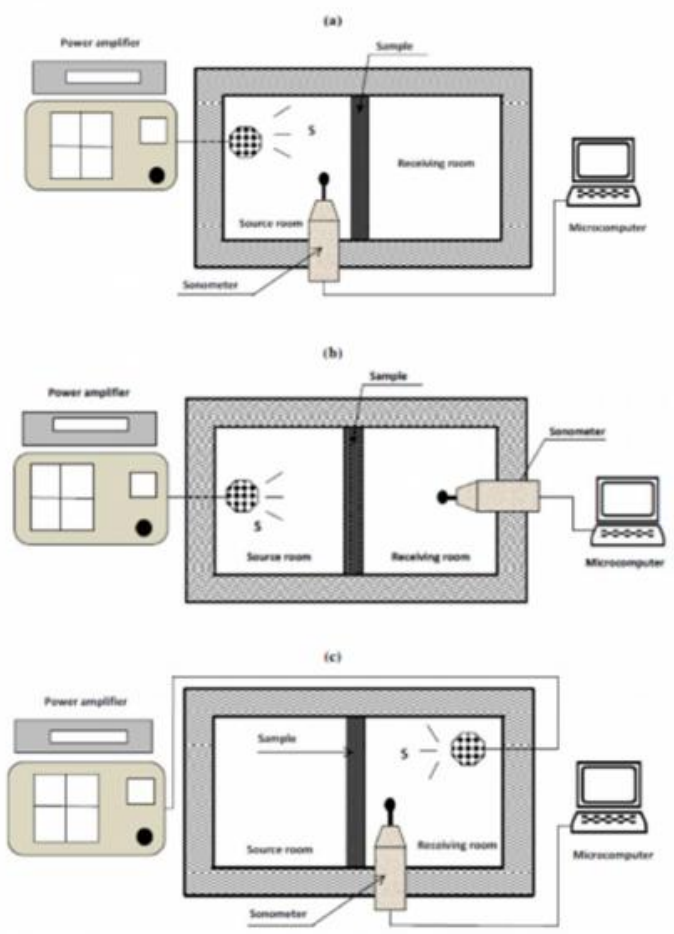

Fig. 3. Measurement of: (a) the average sound pressure level $L_{1}$ in the source room, (b) the average sound pressure level $L_{2}$ in the receiving room, $(c)$ the reverberation time $T_{r}$

\subsection{Measurement of transmission loss and sound absorption coefficient}

Tests were conducted on circular samples with a diameter of $100 \mathrm{~mm}$ for low frequencies, and $28 \mathrm{~mm}$ for high frequencies. The frequency range at which the determinations were conducted was $50 \mathrm{~Hz} \div 10 \mathrm{kHz}$.

The sound absorption coefficient of the samples was determined using impedance tube method (Fig.4) in accordance with the current standards ISO 10534-2 [23].

The impedance tube consists of a hollow metallic cylinder where the test sample is placed at one end of the tube, while at the other end plane sound waves are generated by a loudspeaker. The sound pressure is measured by two microphones at two different locations near to the sample. Then, the calculation of the sound absorption coefficient is performed by invoking a transfer function based on the pressure differences between the two microphone positions [24]. These pressure differences depend on the degree of reflection and absorption of the standing waves that are influenced by the sample under test.

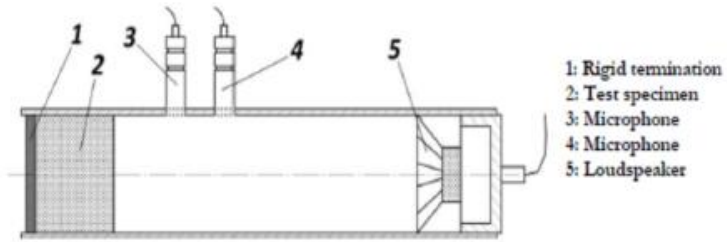

Fig. 4. Experimental setup for acoustic sound absorption and transmission loss using impedance tube 


\section{Experimental result and discussion}

\subsection{Absorption of SCCR}

Figure 5 shows the variation in water absorption of the mixtures according to the content of the crumb rubber. We note that the water absorption of SCCR increases as the percentage of crumb rubber replacement increases. This is due to the presence of air in the SCCR microstructures. Indeed, the air content increases as the percentage of crumb rubber replacement increases. The main reason for the increase is due to the crumb rubber witch repels water during mixing and thereby allows entrapped air on the surface of crumb rubber. The water absorption increases from $200 \mathrm{~kg} / \mathrm{m}^{3}$ to $245 \mathrm{~kg} / \mathrm{m}^{3}$ for content crumb rubber ranging from $0 \%$ to $30 \%$ which corresponds to a reduction of about $19 \%$.

Test results also revealed that the water absorption of SCCR ranges from medium to normal weight depending on the percentage of crumb rubber replacement. [25]

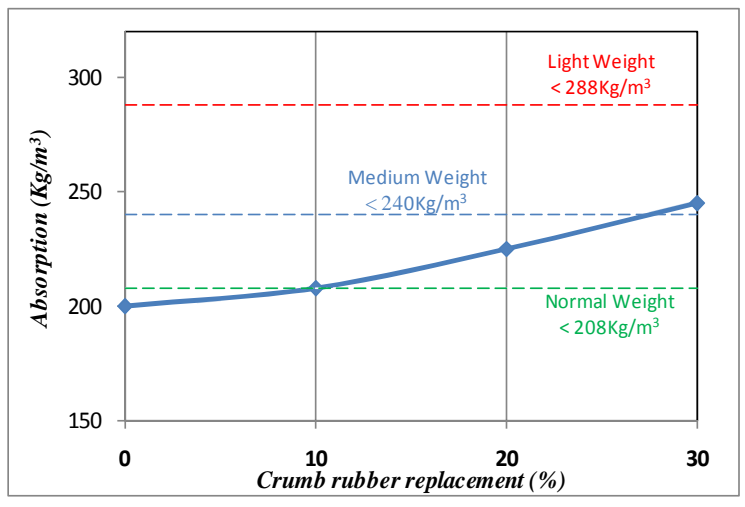

Fig. 5. Effect of crumb rubber on the water absorption

\subsection{Standardized Level Difference}

Fig.6 is represented the variation of the Standardized Level Difference depending on frequency for the different mixtures. In the frequency range $400 \div 1000 \mathrm{~Hz}$ and $1600 \div 2500 \mathrm{~Hz}$, We can observe an increase of the Standardized Level Difference. Indeed, the incorporation of crumb rubber seems to have a positive effect on the weakening of samples.

While for the other frequencies, we can observe a decrease in the values of Standardized Level Difference. This result is foreseeable because the improvement is in function, either of the communicating existence of the pores, or of the increase in the mass and it is not the case.

From the analysis of Fig. 6 we can note that for the frequency range $500 \div 2500 \mathrm{~Hz}$, the sample made from $30 \%$ of crumb rubber have better Standardized Level Difference and can reach a maximum value of $33 \mathrm{~dB}$.

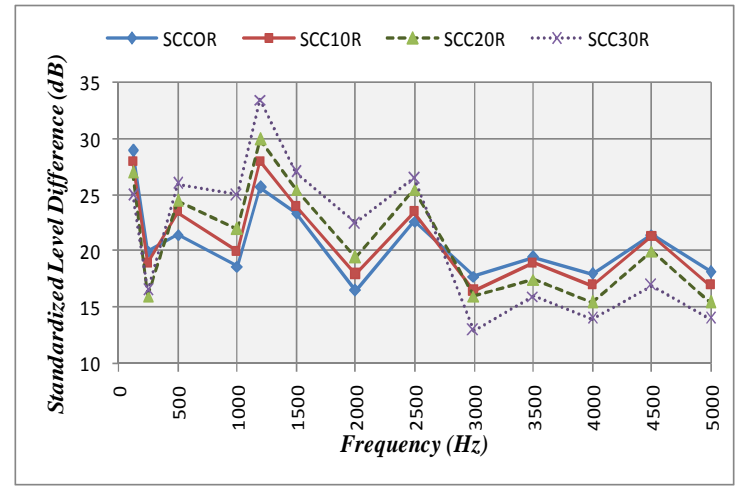

Fig. 6. Standardized Level Difference for SCCR

\subsection{Sound absorption coefficient}

The sound absorption coefficient of a material describes its ability to absorb sound and is measured over a number of specific frequencies. The result is expressed as a number between 0 and 1 where 0 is total reflection and 1 is total absorption.

As show in Fig.7, SCCR has better sound absorption compared to conventional concrete. The noise reduction coefficient (NRC) is given in Fig.8. Test result show that NRC increases as the percentage of crumb rubber replacement increases. Hence, the sound was easily absorbed through the entrapped air on crumb rubber surface inside the microstructure of SCCR [26].

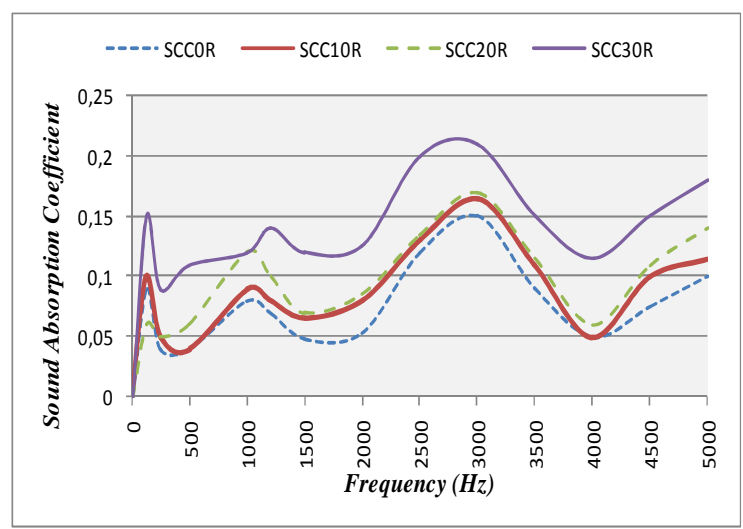

Fig. 7. Sound absorption coefficient depending on frequency for the SCCR 


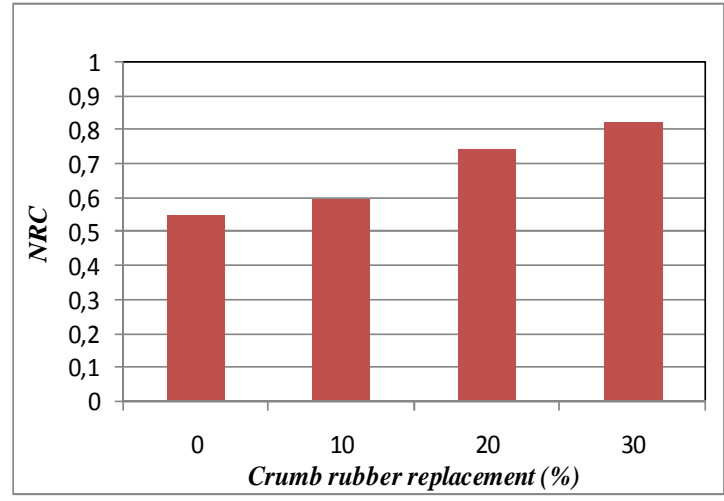

Fig. 8. Noise reduction coefficients for SCCR

\subsection{Transmission loss coefficient}

In general, the acoustic transmission loss coefficient (TL) is affected by the input frequency range and the mass of material, as given by $[27,28]$

$$
T L=2 \log (f . m)-48
$$

Where $\mathrm{f}$ is the frequency and $\mathrm{m}$ is the mass per unit area $\left(\mathrm{kg} / \mathrm{m}^{2}\right)$.

According to the Eq. 5, a 50\% reduction of mass of material results in a $6 \mathrm{~dB}$ decrease of the acoustic transmission loss [27]. However, this value might be ignored when the mass per unit area is high enough that the absolute value of the acoustic transmission loss is much higher than this. In addition, due to the high thickness of the concrete specimens, the acoustic energy absorption must be considered, and Eq. 5 does not take into account the effect of acoustic energy absorption.

Fig. 9 showed the experimental results of the transmission loss coefficient of different specimens measured by the impedance tube method. As the percentage of crumb rubber replacement increases in the SCCR, the air content increases due to the entrapped air on the crumb rubber surface, therefore, the sound is easily absorbed into the SCCR. Hence, the reminder of the sound that passed through the concrete was measured as transmission loss. As the porosity of concrete increases due to an increase in air content, the transmission loss coefficient decrease as the sound is easily passed through the air void present inside the SCCR.

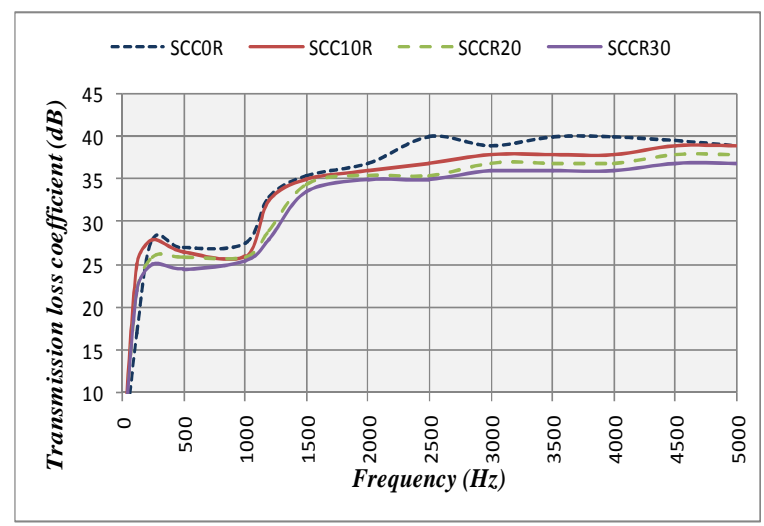

Fig. 9. Transmission loss coefficient depending on frequency for the SCCR

\subsection{Sound Transmission Class}

Figure 10 shows the variation of STC of the mixtures according to the content of the crumb rubber. We note that the STC of SCCR decreases as the percentage of crumb rubber replacement increases due to an increase in air voids in SCCR.

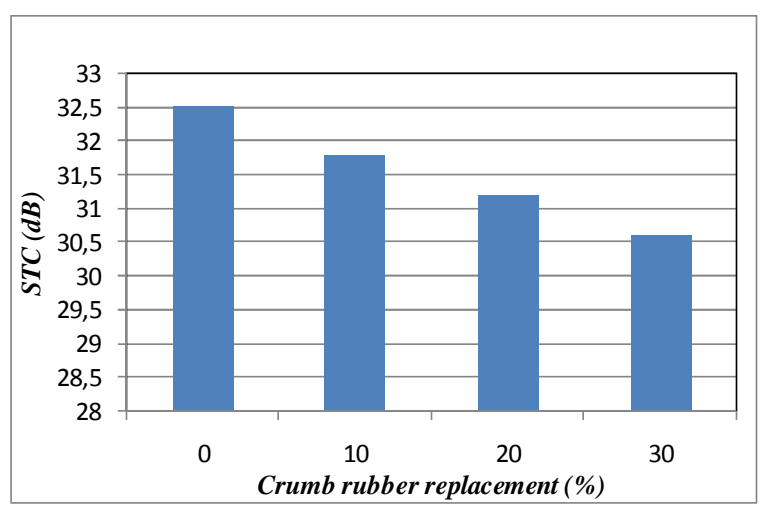

Fig. 10. Sound Transmission Class of SCCR

Table 6 gives the typical hearing quality for a wall of rated sound transmission class. The values found for the STC of all the mixtures are between $30.5 \mathrm{~dB}$ and $32.5 \mathrm{~dB}$, therefore the typical hearing quality for a wall is:" Loud speech understood fairly well, normal speech heard but not understood".

In general, the fundamental principles to achieve high STC are to minimize any direct mechanical connection between the two surfaces of the wall, and to have no openings or leaks. Problem areas for leaks are air vents, around doors, electrical outlets or pipe penetrations.

Table 6.Typical hearing quality for a wall of rated STC

\begin{tabular}{|c|l|}
\hline STC & \multicolumn{1}{|c|}{ Hearing Quality Through Wall } \\
\hline 25 & $\begin{array}{l}\text { Normal speech understood quite easily and distinctly } \\
\text { through wall }\end{array}$ \\
\hline 30 & $\begin{array}{l}\text { Loud speech understood fairly well, normal speech heard } \\
\text { but not understood }\end{array}$ \\
\hline 35 & Loud speech heard but not intelligible \\
\hline 40 & Onset of "privacy" \\
\hline 42 & Loud speech audible as a murmur \\
\hline 45 & $\begin{array}{l}\text { Loud speech not audible, 90\% of statistical population not } \\
\text { annoyed }\end{array}$ \\
\hline 50 & $\begin{array}{l}\text { Very loud sounds such as musical instruments or a stereo } \\
\text { can be faintly heard, 99\% of population not annoyed }\end{array}$ \\
\hline
\end{tabular}

\section{Conclusion}

The present paper has presented results of the investigation on the acoustic properties of self-consolidating concrete with crumb rubber. The effects of rubber aggregates on the density, Standardized Level Difference, sound absorption and acoustic transmission loss of the self-consolidating concrete were investigated, as these are essential performance measures for architectural construction materials. The following conclusions have been drawn from the investigation:

- An examination of the physical behavior showed a reduction of the water absorption up to $19 \%$ for a volume rubber content of $30 \%$, which classifies the SCCR in the medium category. 
- The incorporation of crumb rubber seems to have a positive effect on the Standardized Level Difference witch improve the weakening of SCCR.

- The noise reduction coefficient (NRC) increases as the percentage of crumb rubber replacement increases; the sound was easily absorbed through the entrapped air on crumb rubber surface.

- $\quad$ SCCR has better sound absorption with higher noise reduction coefficient than SCC. Although, the acoustic transmission loss coefficient for SCCR decreases as percentage of crumb rubber replacement increases.

- The STC decreases as the percentage of crumb rubber replacement increases due to an increase in air voids in SCCR.

- We can conclude that it was possible to realise a new sound absorber material by combining selfconsolidating concrete and crumb rubber characterised by low density and good acoustic absorption.

\section{Nomenclature}

$\begin{array}{lll}\mathrm{D} & \text { Level Difference } & \mathrm{dB} \\ \mathrm{DnT} & \text { Standardized Level Difference } & \mathrm{d} B \\ \mathrm{TL} & \text { Transmission Loss } & \mathrm{d} \\ f & \text { Frequency } & \mathrm{H} z \\ \mathrm{~T}_{\mathrm{r}} & \text { Reverberation time } & \\ \mathrm{T}_{0} & \text { Reference reverberation time } \\ \mathrm{NRC} & \text { Noise Reduction Coefficient Ambient } \\ \alpha & \text { Sound absorption coefficient mperature }\end{array}$

\section{Acknowledgment}

The authors wish to thank the civil engineering department of the higher institute of the technological studies of Sfax for their assistance in the experimental tests.

\section{References}

[1] ANPE, www.ANPE.tn.com.

[2] H. A Toutanji., "The use of rubber tire particles in concrete to replace mineral aggregates," Cement and Concrete Composites, Vol.18, pp. 135-139. 1995.

[3] K. B Najim. and M. R Hall., "A review of the fresh/hardened properties and applications for plain(PRC) and self-compacting rubberised concrete (SCRC)," Construction and Building Materials,Vol. 24, pp.20412051, 2010.

[4] E.P Kearsley and P.J. Wainwright, The effect of high fly ash content on the compressive strength of foamed concrete. Cem. Conc. Res, Vol 31, pp. 105-112, 2001.

[5] V. Duman, A. Mladenovic and J. Suput, Lightweight aggregate based on waste glass and its alkali-silica reactivity. Cement Concrete Res., Vol 32, pp. 223-226, 2002.
[6] S. Fiore, M.C. Zanetti and B. Ruffino, 2008. Waste characterization in steel casting and recycling opportunities in Europe. Am. J. Applied Sci., Vol 5, pp.512-518, 2008.

[7] M.N James, W. Choi and T. Abu-Lebdeh, 2011. Use of recycled aggregate and fly ash in concrete pavement. Am. J. Eng. Applied Sci., Vol 4, pp. 201-208, 2011.

[8] A. Laukaitis, R. Zurauskas and J. Keriene, 2005. The effect of foam polystyrene granules on cement composite properties. Cement Conc. Comp., Vol 27, pp. 41-47, 2005.

[9] M. C. Bignozzi and F. Sandrolini, "Tyre rubber waste recycling in self-compacting concrete," Cement and Concrete Research,Vol. 24, pp.735-739, 2006.

[10] NN. Eldin and AB. Senouci, Rubber-tire practices as concrete aggregate. J Civil Eng Mater; 5(4):478-96, 1993.

[11] AS. Ei-dieb, MM. Abdelw and ME. Abdel-hameed, "Concrete using tyre particles as aggregate" In: Proceedings of the international symposium, concrete technology unit. ISBN: 072772995 0: Thomas Telford Publishing; p. 251-9, 2001.

[12] M. Jedidi, A. Gargouri and A. Daoud, " Effect of rubber aggregates on the thermophysical properties of selfconsolidating concrete" Int. J. of Thermal \& Environmental Engineering, Vol 8, pp. 1-7, 2014. DOI: $10.5383 /$ ijtee.08.01.001

[13] A. El-Gammal, AK. Abdel-Gawad, Y. El-Sherbini and R.A. Shalaby, "Compressive strength of concrete utilizing waste tire rubber," J Emerg Trends Eng Appl Sci; 1(1):96-9, 2010.

[14] LE. Zheng, "Experimental investigation on dynamic properties of rubberized concrete," Constr Build Mater; 22:939-47, 2008.

[15] S. Bonnet, A. Turatsinze and J.L. Granju, "Un composite cimentaire résistant à la fissuration: synergie granulats en caoutchou-renfort par fibresTyre," Bulletin des laboratoires des ponts et chaussées, 250-251 ref 4504, pp.43-54, (2004).

[16] MM. Reda Taha, AS. El-Ei-Dieb, MA. Abd El-Wahab, and Abdel-Hameed ME., "Mechanical, fracture, and microstructural investigations of rubber concrete," J Mater Civil Eng;20:640-9, 2008.

[17] T. Uygunoglu and IB. Topçu, "The role of scrap rubber particles on the drying shrinkage and mechanical properties of self-consolidating mortars," Constr Build Mater; 24(7):1141-50, 2010.

[18] MC. Bignozzi and F. Sandrolini, "Tyre rubber waste recycling in self-compacting concrete," Cem and Conc Res; 36(4):735-9, 2006.

[19] P. Nanthagopalan and M. Sathanam, "Fresh and hardened properties of self-compacting concrete produced with manufactured sand," Cem Concr Compos2010; 33(3):353-8.

[20] NF EN 934-2+A1, "Admixtures for concrete.mortar and grout-Part 2: concrete admixtures-Definitions, requirements, conformity, marking and labelling," (2012). 
[21] P. Sukontasukkul, Use of crumb rubber to improve thermal and sound properties of pre-cast concrete panel, Construction and Building Materials, vol. 23, 2009 pp.1084-1092.

[22] American Society for Testing and Materials, 20051. Classification for Rating Sound Insulation. ASTM, West conshohocken, PA, USA. E413.

[23] Standard SR EN ISO 10534-2, Determination of sound absorption coefficient and acoustic impedance with the interferometer. Part 2. Transfer function method, 2002.

[24] International Organization for StandardisationDetermination of Sound Absorption Coefficient and Impedance in Impedance Tubes, Part 2: TransfertFunction Method. ISO 10534-2; International Organization for Standardisation: Geneva, Switzerland, 1998.
[25] American Society for Testing and Materials, 2004c. Specification for Load Bearing Concrete Masonry Units. ASTM, West Conshohocken, PA, USA. C90.

[26] U.B Topcu, "The properties of rubberized concrete," Cement and Concrete Research, Vol.25, N², pp. 304310, 1995.

[27] V. Hongisto, Sound insulation of doors-part 1: prediction models for structural and leak transmission.J Sound Vib 2000; 230(1):133-48.

[28] FJ. Fahy, In: Sound and structural vibration: radiation, transmission and response. London: Academic Press; 1985. 